\title{
Malignant Superior Sulcus Neoplasm
}

National Cancer Institute

\section{Source}

National Cancer Institute. Malignant Superior Sulcus Neoplasm. NCI Thesaurus. Code C7527.

A malignant neoplasm originating from the apical lung. Most malignant superior sulcus neoplasms are bronchogenic carcinomas. This tumor may be associated with Pancoast syndrome. It is also known as Pancoast tumor. 